\title{
Exchange Automation and Adaptive Efficiency at the Kenyan Securities Market
}

\author{
Samuel O. Onyuma \\ School of Business \& Economics, Laikipia University, Kenya
}

\begin{abstract}
Developments in electronic trading has played an increasing role in changing the microstructure of securities markets. Worldwide, securities exchanges are gradually replacing their traditional physically convened markets with electronic markets. In order to contribute to wealth maximization objective of investors and economic growth, securities markets need to be efficient in terms of price discovery process. The Nairobi Securities Exchange has automated it operations by installing an automated trading and depository systems to improve its efficiency. Information is however lacking on how these changes have affected the informational efficiency of the Exchange. This study tried to determine whether the automation of the Exchange had improved its informational efficiency. Using secondary data collected from the Exchange on share prices for computing an All Share Index between 1994 and 2019, non-parametric approaches were used to measure market efficiency before and after market automation. The results show that market returns in the post-automation period were higher and more volatile than those in the pre-automation period. The higher returns can be attributed to improved price discovery process, while the higher volatility may be due to changes in market microstructure through use of electronic systems. While Normality tests indicate that returns are not normally distributed in both the periods, Runs test results reveal that returns are more random in the period following automation than the prior period, implying that the market has improved in efficiency. The introduction of automation in the Kenyan securities market has thus led to improved market efficiency, providing support for the adaptive market hypothesis. The Exchange should consider pursuing full market automation by enabling online and internet securities trading and use of mobile money transfer platforms in paying for stock transactions, in addition to the adoption of margin trading and a hybrid trading system (call and continuous) - to enhance liquidity and transparency in trading.
\end{abstract}

Keywords: Automated Trading System, Central Depository System, Adaptive Market Efficiency, Market Microstructure, Nairobi Securities Exchange.

JEL Classification: 614 ; G15

DOI: $10.7176 / \mathrm{EJBM} / 12-15-06$

Publication date:May $31^{\text {st }} 2020$

\section{Introduction}

Securities markets enable firms to easily raise finance, while ensuring efficient capital allocation in an economy. They also contribute to price discovery, provide liquidity, assist in risk transfer, facilitate corporate governance, and a measure of company performance. Financial economists, investment managers and market regulatory authorities are usually concerned with the efficiency of securities markets because the ability of these markets to perform the above critical functions depends on their level of efficiency.

A securities market is deemed to be informational efficient if security prices fully reflect all the available information (Fama, 1970). The more efficient the market, the more random the sequence of price changes generated by such a market. The most efficient market is one in which prices are completely random and unpredictable. Until the 1970s, securities markets were believed to be informational efficient until market anomalies started to be documented. These anomalies seemed to be at odds with the efficient markets theory (EMT) and led to the emergence of behavioural finance. According to the proponents of behavioural finance, markets are not absolutely efficient as portrayed by the EMT but rather relatively efficient (Chuvakhin, 2000).

Recently, there has been an attempt to reconcile these two opposing schools of thought which has given rise to the Adaptive Markets Efficiency (AME). The AME contends that market efficiency is not an all or none condition but is a characteristic that varies overtime, and may be influenced by various market environmental factors. Many studies have been done on securities market efficiency in Kenya and elsewhere. However, few studies have examined the impact of market microstructure changes on market efficiency, particularly for an emerging market like the Nairobi Securities Exchange (NSE). Additionally, studies done on weak form market efficiency have resulted in adopting a fixed approach when testing for efficiency levels, which results into the conclusion that a market is weak form efficient or inefficient. This tends to ignore such market environmental factors that may influence market efficiency.

According to the AME championed by Lo (2017), market efficiency is highly context dependant as influenced by environment factors such as regulatory changes, microstructure improvement and the number of market participants. As a result, the efficiency of a securities market may change as influenced by these environmental factors. Thus, a more appropriate way to look at market efficiency would be whether the market is becoming more 
efficient as a result of these factors rather than concluding that a securities market is weak form efficient or inefficient.

Furthermore, one of the main goals of the Kenya's securities markets regulator, the Capital Markets Authority (CMA), and the NSE when carrying out various market infrastructural changes is to improve market efficiency. The two have overseen the automation of the Exchange depository and trading systems in order to fully computerize the operations of the securities market. This was expected to improve market turnover, liquidity, and informational as well as operational efficiency of the market.

It is on the backdrop of the microstructure changes that has seen renewed market activity which led to the NSE-20 Share Index registering an all-time high 12th February 2007 of 6161.46 points. However, recent political events and the collapse of three brokerage firms have provided lots of challenges to the performance, growth and development of the NSE as many investors seem to have shied away from the market. It is such challenges that have called for improvement in the microstructure of the Exchange to achieve more transparency, high trading speed, and increased market surveillance so as to increase its market efficiency.

In the past, trading in financial instruments has traditionally required face-face communication at a physical location - the Exchange trading floor. However, advances in electronic communication have led to the mushrooming of new depository and trading systems. This development has seen numerous securities exchanges across the world facing out the traditional functional systems and replacing them with electronic-aided markets. The NSE has not been an exception, since in November 2004, the Exchange installed the Central Depository System (CDS), which revolutionized the clearance and settlement of stock trading transactions as well as safekeeping of securities. Also, in September 2006 the Exchange went into full automation of its trading system after decades of operating as a floor-based oral auction. This was in addition to the installation of the Broker BackOffice (BBO) system in 2012. These upgrades, representing market microstructure changes, marked a major milestone in market infrastructure development process of the Exchange, and were expected to boost market liquidity, reduce settlement risk, increase operational and informational efficiency, and elevate the market to international standard.

Whether these microstructure changes have improved the informational efficiency of the market still remained unclear. A number of studies have been done in Kenya assessing whether or not the Exchange is efficient at different forms, thus tending to ignore the environmental factors that may influence market efficiency. In fact, Hendershott \& Moulton, (2011) have maintained that the effect of changing automation within a market is an important and understudied area. This study, therefore, tried to fill this gap. The objective of this study therefore was to evaluate the impact of market microstructure changes on market efficiency at the NSE. Specifically, the study computed the market index returns; determined the distribution of market returns; assessed if market automation had affected the price discovery process, and also reduced the return volatility at the Exchange, all both before and after market automation; and examined whether the efficiency of the market improved following the automation of the functions of the Exchange. This study hypothesized that market returns were normally distributed; market returns were not statistically different from each other; market return volatility were not statistically different from each other; and market returns were random, all both before and after market automation.

The efficiency of the securities market has a lot of implications on finance theory and investment strategies and therefore plays an important role to academicians, investors, securities exchanges and regulatory authorities. Therefore, the findings of this study is of interest to scholars as it adds to the stock of knowledge in the pursuit of understanding the efficiency of the securities markets, thus adding to the ever growing literature on market efficiency. Secondly, financial analysts and investors can utilize the findings in designing different trading strategies that take into account the existence of random walk or its persistence in the short-run and mean reversion in the long-run. Lastly, the NSE and CMA can utilize the findings to assess the effect of new market development policies.

\section{Reviewed Literature}

\subsection{The Nairobi Securities Exchange}

The Nairobi Securities Exchange, founded in 1954 as a voluntary association of stockbrokers and registered under the Societies Act, is the principal securities exchange in Kenya. Besides equity securities, cash and derivatives, the Exchange also offers a platform for the issuance and trading of debt securities. The NSE is a member of the African Securities Exchanges Association (ASEA) and the East African Securities Exchanges Association (EASEA). It is a full member of the Association of Futures Markets (AFM) and the World Federation of Exchanges (WFE), a partner Exchange in the United Nations Sustainable Stock Exchanges Initiative (SSE), and a member of the Financial Information Services Division (FISD) of the Software and Information Industry Association (SIIA). In 2016, the NSE was awarded The Most Innovative African Stock Exchange by Ai Capital Markets and Index Series Awards. This is the second time the NSE was receiving this prestigious accolade, having won the same in 2013

The Exchange is the largest in East African Community and in 2019, the leading in Africa in terms of returns. 
During this period, the Exchange outperformed its peers in Africa on the back of better returns from its large-cap stocks that were attractive to foreign investors. The NSE's All-Share Index, which tracks the market value of shares of all listed firms, gained 18.5 percent to close the year 2019 at 166.41 points. Given this superior gain, the Exchange raced ahead of Johannesburg Stock Exchange (JSE), which returned 8.24 percent in 2019 and Morocco's Casablanca Stock Exchange 7.72 percent. Nigeria Stock Exchange (NiSE) and the Egyptian Exchange (EGX) declined in return performance by 14.6 and 19 percent respectively. The fact that it outperformed other key markets means investors were more comfortable with main metrics such as stability of currency and free entry and exit of funds. Despite the gains, the NSE remains relatively smaller compared to the JSE, NiSE and EGX. The JSE, for instance, in April 2020 had a market capitalization of Ksh25.5tn from the 375 listed firms, NSE has 63 firms with a market value of Ksh2.5tn, NiSE had 116 listed firms valued at Ksh3.73 trillion, while EGX was at Ksh4.23tn (Onyuma, 2020).

On $12^{\text {th }}$ February 2007, the NSE 20-Share Index recorded an all-time high of 6161.46 points (Onyuma, 2017). In July 2011, the Nairobi Stock Exchange changed its name to the Nairobi Securities Exchange Limited, through a demutualization process, that reflected the strategic plan of the Exchange of evolving into a full service securities exchange which supports trading, clearing and settlement of equities, debt, derivatives and other associated instruments (Onyuma \& Kibet, 2017). In September 2011 the NSE converted from a company limited by guarantee to a company limited by shares. To complete the governance structure transformation agenda, the Exchange in September 2014, became a listed company through a self-listing process, a process which had dragged on for 9 years (Onyuma \& Ochieng', 2017).

Innovation and product diversification seems to be at the heart of the Exchange. The Exchange is currently dealing in listed shares, government and corporate bonds, real estate investment trusts (REITs), and exchange traded funds (ETFs). The Exchange successfully launched the M-Akiba Retail Bond, which NSE was appointed to spearhead through the Ministry of Finance in which small retail investors can invest in through mobile money telephony services. In 2017, the NSE completed the upgrade of its Automated Traded System, which was launched in 2019, and now supports the trading of new equity and quasi-equity instruments in a robust platform with dynamic surveillance capability (Onyuma, 2021). The Exchange later launched the Derivatives Market in 2019 where it commenced with trading in index and single stock futures. It had also participated in the development of regulations for the introduction of securities lending and borrowing in an effort to enhance liquidity in the capital markets.

\subsection{Trading Systems at the Nairobi Securities Exchange}

Following its inception, the Exchange adopted a trading system which was manual in nature, first a call-over system, and then an open-outcry trading system. Over the years, the NSE has grown in several aspects although it has remained as an order-driven market. Order-driven markets may take the form of oral auctions, single price auctions, continuous electronic auctions and crossing networks (Francioni et al, 2008). At the time of its establishment, the NSE operated a periodic call auction as there were few listed securities and trading activity was minimal. There was also no physical trading floor as transactions were carried out in a coffee-house forum over the telephone and prices were determined through negotiation. Under the periodic call market, all traders traded at the same time when the market was called and transactions were settled at a single clearing price. The single clearing price was the price at which most bids and offers would be executed. The market would call all securities simultaneously or it may call securities one at a time, in a rotation.

In 1991, trading was moved from the coffee-house to a floor-based open-outcry system. The structure changed from a call market to a continuous auction. With the open-outcry system, traders arranged their trades face-face on the Exchange trading floor, which was guided by the NSE Trading Rules. Some traders shouted out their bids and offers to attract other traders while others listened to the bids and offers they were willing to accept. A trade occurred when a buyer accepted a sellers offer or a seller accepted a buyers bid. In the case of the buyer, the buyer would call out take it to accept the offer while in the case of the seller, the seller would call out sold out to accept the bid. Usually, buyers and sellers would take turns bidding and offering until they agree on the price and quantity to trade (Onyuma, 2017).

With the floor-based open-outcry system, trading was conducted from 10 am to12 pm. Potential buyers and sellers would place their buy or sell orders through stockbrokers, who in turn, would place their orders through their representatives at the trading floor. Daily limits on price movements were also set at 15 percent of the opening bid or offer prices. This system was adopted as it enhanced transparency by allowing brokers an equal opportunity to bid for securities and its ability to handle increased trading activity. Further, it was felt that trading in the coffeehouse environment did not generate enough public awareness and the prices obtained by buyers and sellers were not the best (Onyuma, 2017). The NSE later moved to more spacious premises at the Nation Centre in July 1994 and set up a delivery and settlement system (DASS).

Despite these developments, the Exchange still operated a manual clearing and settlement system which had a serious impact on the liquidity and operational efficiency of the market. For example it would take about two 
weeks between an actual security sale and confirmation. Some notable problems with manual trading are that transparency for floor trading, pre-trade transparency in particular, was low at the manual trading at the Exchange. Stock quotes were not distributed publicly as they were available only on the floor. Market manipulation and other abuses of power and position were rife on the NSE floor. Investors also waited for too long as transactions were settled after many days. Given the appreciable market fragmentation, poor transparency, imperfect inter-market linkages with other EAC exchanges, and dubious trading floor behaviour, transaction costs were high (Onyuma, 2017). Changes, both structural and regulatory, were therefore called for. This led to the need to institute a better trading system and a proposal was floated in 1994 to adopt a central securities depository system.

On $1^{\text {st }}$ August 2000, a delivery versus payment system (DvP) was introduced as the initial step towards moving to the electronic system of settlement. The aim of setting up the DvP was to move the market from $\mathrm{T}+7$ closer to the $\mathrm{T}+5$ transaction cycle environment, enhance investor confidence and liquidity by making the settlement period shorter and safer, and enable brokers to concentrate on their core business. However, the DvP faced the main challenge of settling transactions within 7 days of trading and providing stock investors with their shares within seven days after trading. There were still delays in settling trades and this made some investors to lose dividends as share certificates were being prepared. This had the potential of significantly affecting the market liquidity and efficiency negatively (Jallow, 2009).

The Capital Markets Authority, having approved the revision of the NSE Trading Rules and the Central Depository and Settlement Corporation (CDSC) Operational Rules for the purposes of reducing the equities settlement cycle, the NSE on July $4^{\text {th }} 2011$, reduced the securities settlement cycle from the T+5 to the T+3 (NSE, 2011a). The move to the $\mathrm{T}+3$ Settlement Cycle was in line with international best practice as recommended by the International Organization of Securities Commission (IOSCO) in the Objectives and Principles of securities regulations. Therefore, on the sale side, investors are able to get their money, three days from the sale of their shares, whereas, on the buy side, investors are able to get their shares, three days from their purchase. The efficiency and reduction of risk that comes with an electronic trading and a shorter settlement cycle, could improve liquidity in the market for listed equity securities, making the market more attractive to both domestic and foreign investors. The result of all these efforts was the development of the central depository system and an automated trading system - an electronic order-driven trading system that comprises two principal modalities - a continuous order book platform and periodic single-price call auctions.

Automating the Share Depository, Clearance and Settlement System. The trading system employed by the NSE for over five decades was manual - first, a call over system and then the open out-cry system. The call over and open out-cry systems of trading have great limitations in terms of the traded volumes they can handle and the speed at which trade can be executed (Onyuma, 2015; Mbugua, 2007) and hence the need for market automation. After various complications, the NSE launched a central depository system (CDS) on 24th November 2004.

The many functions of the CDS include: to facilitate the faster change of ownership of securities electronically between parties, without the need for the movement of physical documents. Share transfer can also be electronically done in an efficient, safe, transparent and cost effective manner. It is meant to minimize the delivery and settlement risks, speeds up securities distribution, attract more firms to list and facilitate the process of securities markets integration (Onyuma, 2015). The launch of CDS has, however led to some fraudulent activities by broker some of whom sold their clients' shares without their authority, leading to collapse of four brokerage firms, and a call for more automation and other legal reforms.

Automating the Share Trading System. An automated securities trading system is one in which trading is conducted by a network of computers connected to a trading engine, and where brokers simply enter, using a computer, the volume they want to trade and their preferred price (Jallow, 2009). The computer then processes the various offers and bid prices and determines the best price at which the trade should be executed. The computer then matches the orders and allocates them in order of programmed priorities for trade execution. Some markets are partially automated in the sense that they allow transactions to be executed manually on the exchange floor, while orders are however entered on the electronic screens.

On $11^{\text {th }}$ September 2006, the automated trading system (ATS) was launched by the Exchange in which the human interface was eliminated and replaced with computers and computer networks (Onyuma, 2013). The structure of the market changed from the floor based oral auction system to an electronic auction. All bids and sell offers are submitted to the specific brokers who in turn submit through an electronic network and are displayed in a central limit order book accessible to all traders. The central limit order book displays all the bids in a descending order and all the offers in an ascending order. All orders are electronically matched and executed using a set of computer algorithms that consider price and time priority. The trading of securities including the orders is displayed real-time, with the aim of increasing the trading speed and market efficiency. With the ATS, trading hours have increased from 9 am to 3 pm and settlement period reduced from $T+5$ to $T+3$ days.

In February 2007 NSE upgraded its website to enhance easy and faster access of accurate, factual and timely trading information. The upgraded website has boosted the data vending business of the Exchange. A Wide Area Network (WAN) platform was implemented in 2007 and this eradicated the need for brokers to send their traders 
to the trading floor of the Exchange to conduct business. Although trading is currently mainly conducted from the brokers' offices through the WAN, however, brokers under certain circumstances can still conduct trading from the trading booths at the floor of the Exchange. The NSE marked the first day of automated trading in government bonds through the ATS in November 2009. The automated trading in government bonds marked a significant step in the efforts by the Exchange and CBK towards creating depth in the capital markets by providing the necessary liquidity.

In a move expected to improve the efficiency of settlement of equities and corporate bonds and align the process to international best practice, CDSC has worked together with the CMA and CBK to develop a more robust cash settlement model for equities and corporate bonds, in which the cash side of the settlement process for transactions concluded on the Exchange is now being done through the Central Bank of Kenya's Real Time Gross Settlement (RTGS) system, with effect from January 15, 2015 (Onyuma, 2020). Recently, the NSE introduced a live trading board that enables the public to view the order book in order to encourage transparency and efficiency. Also, some brokerage firms provide their clients with access to the electronic order book as well as allowing them to submit orders remotely, through an online trading system.

Automating the Broker Back Office System. In October 2011, through a stakeholder driven process, the Exchange implemented a Broker Back Office system (BBO) which is tightly coupled and interfaced with the ATS and CDS (NSE, 2011b). This system automates order collection, contracting, settlement and accounting. It has an audit trail functionality that tracks all changes made to trade data, and keeps a record of who changed it and when. Such changes are made available in a form that is easy to understand. The administrator can place restrictions on the value of financial entries that individual users can book into the system. All entry and modification of sensitive data have been configured to require an additional level of authorization through a maker checker policy.

According to NSE (2012b), the maker-checker authorization covers all sensitive activities in the system, including all aspects of user management, payment authorization, creation or editing of sensitive client data, changes to brokerage or agent commissions, creation of new accounts, and for authorizing voucher entries. To prevent fraudulent activities on dormant client accounts, the system automatically classifies accounts as dormant depending on the level of activity and requires additional authorization for all transactions made on such accounts. The system enforces a strict password policy, uses encrypted transmission over the wire, automatically times out inactive sessions and restricts concurrent logins into the system. The software also highlights which users have access to sensitive activities. The BBO system recognizes the importance of providing visibility to the top management on the nature of complaints received from clients.

The system therefore provides insightful reports on the frequency and nature of complaints, their financial impact and the time taken to resolve them. The system therefore automates the back office of brokers, reducing human intervention and empowering senior management of brokerage firms to monitor and audit activities through suitable alerts and exception reports (NSE, 2012b). Overall, the system bolsters existing security measures and reduces the risk of trading in securities listed on the Exchange. It should in future enable further innovation through Internet access to the ATS, helping trading participants expand their services across all 47 Counties, facilitate IPO, portfolio management and complaints processing, and enable mobile phone trading.

Automating the Market Surveillance System. Prior to 2012, CMA previously conducted surveillance through a market control system that was provided by the trading platform vendors. This system was however found to be inadequate due to market sophistication and innovation in Kenya. The surveillance function of CMA plays a key role in ensuring that trading of securities at the Exchange is carried out in a manner consistent with the laws, regulations and guidelines governing securities market and that market players act in compliance with the Capital Markets Act and other Regulations. In order for the CMA to keep abreast with the changing market regulatory landscape, it is essential that its functions are continuously strengthened calling for the need for a new robust surveillance system. As part of its mandate to maintain an orderly, fair and efficient market and thus protect investor interests, CMA on $27^{\text {th }}$ June 2012 implemented an advanced and robust market surveillance system, called Capizar Market Surveillance (CMS) (CMA, 2012). The decision to set up an advanced and enhanced market surveillance system was informed by evolving sophistication in the securities market and to enhance the regulator's investor protection initiatives through its ability to identify and prevent market malpractice.

The CMA therefore stepped up its oversight role to ensure real-time surveillance and any irregularities in trading are identified and curbed early enough through this enhanced surveillance system. The system has enhanced monitoring of trading activities to identify unusual trading patterns and market conditions that indicate violations of the Capital Markets Act (Cap 485A) and other Regulations. It has also enabled CMA to monitor trading activities in the market on real-time basis by providing early warning signs through the use of alerts having undertaken multiple analysis and rapidly identifying abnormal trading behaviour, which are saved to assist in investigations and to gather further evidence for prosecution in cases of breach of market Regulations (CMA, 2012).

The system has pre-configured rules to determine common trading patterns that constitute market abuse, including front-running and insider-trading. This is because the market surveillance system is capable of detecting 
fraud and abnormal trading in real-time thereby enhancing protection of investors. This means that cases where staff of brokerage firm fraudulently engaging in unauthorized dealing on client's securities as witnessed between 2007 and 2009 at the NSE (Onyuma, 2017) are preventable. The system also reports post-order and pre-order analysis of transactions thus increasing CMA surveillance capability. Although the Exchange and CMA have been conducting real-time market surveillance prior to the installation of this system, the new technology sets an interface in which the NSE, CMA and CDSC all simultaneously monitor transactions online.

This system gives alerts of any irregular trading patterns and market replay which from an investor point of view is to assure investors that the integrity of the market is at par with others globally. Therefore, should there be any irregular trading or fraud detected the system issues an alert to CMA. By analysing transactions and saving market reports, the system enable easy investigations in cases of breach of market rules by saving evidence. This means that with CMS system, insider trading, which has been prevalent in Kenyan securities market (Maobe, 2012) can be potentially reduced. The implementation of this robust market surveillance system was also expected to increase the depth and numbers of investors while attracting new securities issuers to the securities market due to improved market integrity, investor confidence, more trading turnover and liquidity, thus increased market efficiency.

The automation of depository and settlement operations in 2004, the implementation of the Automated Trading System in 2006 and trading Wide Area Network in 2007, installation of a Broker Back Office (BBO) in 2011 and the launch of automated market surveillance system (Capizar) in 2012, all have widely transformed the Kenyan securities market to globally accepted financial market standards and competitively positioned it as a safe and preferred investment destination. Operationalising an electronic trading platform should allow the market Regulator, Exchange and securities investors to reap the full benefits of technology. Such developments in the securities markets through undertaking changes in market microstructure are likely to make them deeper and more efficient. This in turn has been found to help them reduce the cost of capital, spur investments and promote savingsinvestment balancing (Kalra, 2010).

\subsection{Theoretical Analysis of Efficiency of Securities Markets}

The efficient market hypothesis (EMH) championed by Fama (1965) forms the cornerstone of modern finance. When a securities market is efficient, all available information is fully and instantaneously reflected in securities prices, and no investor is capable of making abnormal profit. When the information set is limited to past price and return, the market is said to be weak-form efficient and the asset return is purely unpredictable from the past information.

According to the EMH, a market is said to be informational efficient if security prices at any time fully reflect all the available information (Fama, 1970). Information refers to anything that may affect securities prices and is unknowable in the present and thus appears randomly in the future. It follows that if new information is unpredictable then security prices should move randomly and unpredictably and the best predictor of tomorrow's price would be today's price. In its weakest form, the EMH posits that past prices cannot be used to predict future prices. Therefore, the use of technical and fundamental analysis is of no real value in securities market analysis.

For a long time, the random walk theory has been used to examine the weak form efficiency of securities markets. However, a major limitation with the random walk theory is that it requires a prior assumption of normal distribution. Indeed studies have shown that returns are not normally distributed but rather they exhibit certain stylized facts such as heavy tails and volatility clustering. This is not surprising given the changes in market microstructure and irrational behaviour exhibited by investors such as overconfidence (Barber \& Odean, 2001), overreaction and under-reaction (Debondt \& Thaler, 1985), loss aversion (Kahneman \& Tversky, 1979), as well as herding mentality (Onyuma, 2009).

Lo (2004) has reported that there is no consensus among finance academics and practitioners as to whether securities markets are efficient. While most of finance professors believe the market is weak-form efficient (Doran, et al. 2009), there are critiques from the behavioral finance who document irrational, but highly predictable, investor behaviour such as overreaction and overconfidence (Barber \& Ordean, 2001). Grossman \& Stiglitz (1980) have even argued that a perfectly efficient market is impossible to exist.

In response to these critics, Campbell et al. (1997) proposed the concept of relative efficiency, which departs from all-or-nothing view. With relative market efficiency, it is useful to measure the degree of efficiency or return predictability. Currently, it is widely believed that the degree of market efficiency changes over time. For example, Yen \& Lee (2008) report empirical findings in support of market efficiency in the 1960s; mixed outcomes in the 1970s to 1980s; and challenging outcomes in the 1990s. Park \& Irwin (2007) provide a similar survey, where early studies (1960-1987) find no evidence of profitability of technical trading rules while most modern studies (19882004) report otherwise. Hence, the findings of these studies point to the claim that the securities market in general becomes less efficient over time.

Empirical results are even mixed for developed securities markets such as those in the USA. Gu \& Finnerty (2002) report that the market has shown improved efficiency since the late 1970s, while Lo (2004) report that the 
degree of efficiency varies in a cyclical fashion and that the market has been more efficient in the 1950s than in the 1990s. Ito \& Sugiyama (2009) reported that the market was efficient in the 1960s and 1970s, highly inefficient in the 1980s, and then became efficient again around 2000. Additionally, Grossman \& Stiglitz (1980) showed that it is impossible for markets to be perfectly efficient. If markets are perfectly efficient there would be no reason to trade and eventually markets would collapse. Inefficiencies motivate investors to trade as long as they can compensate for the cost of trading and information gathering. Black (1986) showed that the sources of inefficiencies are noise traders, that is, individuals who trade on what they consider information but is merely noise.

The non-normal behaviour of returns questions one of the core theories in finance, the Efficient Markets Theory. It is no wonder that alternative models have developed to better describe the non-normal and non-linear behaviour of returns such as the Fractal Market Hypothesis (FMH) (Peters, 1994). Under the FMH, markets are assumed to follow a stable paretian distribution as opposed to a normal distribution. Securities markets are also depicted as complex evolving systems which cannot be modelled by linear methods of efficient market theories. The complexity of the markets stems from heterogeneous expectations by investors who are not fully rational, that is, they apply available information differently, invest at different investment horizons and react gradually to the information (Peters, 1994). Eventually, markets follow a biased random walk as opposed to a pure random process.

Besides the limitations of the random walk model studies have also shown that measuring the absolute efficiency of the market may lead to wrong conclusions. According to Campell et al (1997), absolute efficiency is unrealizable in the real world and thus relative efficiency may be a better way of looking at market efficiency that is, comparing the efficiency of markets with respect to each other - for instance, futures versus spot markets, or auction versus dealer markets. This view is also shared by Lo (2007) who stated that perfect efficiency is an idealisation and sets forth the necessary framework for measuring relative efficiency. For instance, Lo (2007) compared market efficiency to a piston engine and stated that a piston engine can be said to be 60 percent efficient, that is, 60 percent of energy contained in the fuel is used to turn the crankshaft, while the remaining 40 percent is lost in heat, light or noise. Few engineers will be interested in testing whether an engine is perfectly efficient since such an engine will only exist in an ideal world. If the market is to be viewed as a machine whose role is to set prices properly, the inefficiency of this machine can be substantial.

Adaptive Market Efficiency. The evolving nature of return predictability can be rationalized in the framework of Lo (2004) adaptive markets hypothesis (AMH). With investor rationality at the heart of the controversy between advocates of the efficient market hypothesis and its behavioral critics, Lo (2004) provides reconciliation through the AMH in which market efficiency is explained from an evolutionary perspective. It is an application of the evolutionary principle to financial markets, which argues that constantly changing market conditions govern key market features such as return predictability. Therefore, the market efficiency cannot be evaluated in a vacuum, but is highly context dependent and dynamic environment (Lo, 2007). Among others, the AMH implies that return predictability and investment profitability do arise from time to time due to changes in the demographics of investors, financial institutions and market conditions.

More recently, Lo (2017) proposed the Adaptive Markets Hypothesis (AMH), which view financial markets through an evolutionary lens and tries to reconcile market efficiency with human behaviour. Millions of investors worldwide have money in the securities markets, yet economists seem not to have consensus on whether investors and markets are rational and efficient, as modern financial theory assumes, or irrational and inefficient, as behavioural economists believe - and as financial bubbles, crashes, and crises have recently suggest. This is one of the biggest debates in economics and finance and the value or futility of investment management, securities market research, financial advice, and financial regulation hang in the balance. To resolve this decades-old debate, Lo (2017)'s AMH broadens market efficiency debate to include the study of psychology, evolutionary biology, neuroscience, artificial intelligence and other fields that offer insight on human behaviour. His hypothesis shows that the theory of market efficiency is not necessarily wrong, it is merely incomplete. When markets are unstable, investors often react instinctively rather than rationally, creating inefficiencies for other investors and traders to exploit. Lo (2017)'s new paradigm explains how financial evolution shapes behaviour and markets at the speed of thought - a fact revealed by swings between stability and crisis, profit and loss, and innovation and regulation.

Empirically, there is an expanding literature that reports evidence of time-varying stock return predictability, which is consistent with the prediction of AMH (Lim \& Brooks, 2011). However, none of those previous studies explore whether the return predictability is driven by changing market conditions. Since 1997, the Kenyan securities market has experienced a number of exceptional market infrastructural developments such as installation of CDS, ATS, and BBO; political, economic, and ethical crises; and market bubble in 2007. These events may have strong implications to the behaviour and psychology of market participants, which in turn may affect the pattern of price changes (Kim \& Shamsuddin, 2008; Lim et al., 2008). In view of Lo (2007) AMH preposition, it is highly likely that the degree of return distribution and independency are driven by such dynamic market conditions.

The CMA and NSE have been instrumental in implementing policy and institutional changes in the Kenyan securities market. For example, in 2006, CMA together with the NSE oversaw the automation of the trading system 
in order to fully computerize the operations of the securities market. This has significant implication on improved market liquidity and operational efficiency of the market. The various market institutional and infrastructure reforms have led to increased participation from local and institutional investors evident in the increasing number of CDS accounts opened due to growing number of listed firms with heavy oversubscription and securities investors (CMA, 2012). Nevertheless, cases of listed firm being delisted has increase recently.

\subsection{Securities Market Microstructure}

During the last few decades, the organization of securities markets have been profoundly transformed: from national exchanges organized under various mutual forms, the industry switched almost entirely to transnational exchanges organized as corporations owned by their clients or other investors; futures and option markets became more independent and important; physical floors almost disappeared and continuous electronic trading became the norm (Onyuma, 2006a). These changes, which were quite radical comparing to the industry's standards, were part of a wave of deregulation and privatization of economic infrastructures which started in the UK and US around 1980. But, beyond the affirmed virtuous of competition among securities exchanges, the very reasons for their general diffusion and their speed have not been provided yet (Hautcoeur \& Riva, 2011).

At the same time, in academia, a new literature developed studying financial markets' microstructures in theoretical, empirical and experimental perspectives. This growing body of research is a signal of the strong interest that - during such a period of intense financial innovation - securities markets' scholars, regulators and practitioners had for the actual functioning of financial markets, well beyond the neoclassical assumptions of perfect markets with complete information and without frictions. Actually, the large investments in trading process and technologies by securities exchanges, as well as the absolute amount of transaction costs in a world of huge daily financial transactions would be enough to justify the interests of the finance scholars for market microstructure. Nevertheless, if that literature emerged recently as a new field in finance, it was only apparently new.

The expression market microstructure comes from the title of Mark Garman's article published in the Journal of Financial Economics in 1976, but one of the first theoretical works on this topic was the Elements d'économie politique pure by Léon Walras, published exactly a century before in 1876 . In this book, Walras drafted this theory based on the modeling of the working of the Paris Bourse and supplied the foundation of the modern market microstructure theory while discussing in detail the actual functioning of the market (Walras, 1880). It is probably only because of a long period of negligence due to the marginal role that securities markets played in financial systems from 1914 to the late 1970s, that the study of microstructure so lately renewed the interest that late 19th - early 20th century scholars had shown in financial market's organization.

Since then, a robust theoretical and empirical literature on market microstructure has demonstrated on rigorous microeconomic basis the impact of the organizational setting on markets' performances (Majois, 2008). Within the standard framework, trades have both a permanent and a short term impact on the prices of securities. While the permanent impact on prices reflects the pure informational content of trades, the short term impact reflects the transactions costs and market frictions that traders face. These elements divert prices from the fundamental value of the securities and can add volatility while reducing liquidity and increase counterparty risk. Consequently, they represent frictions for capital allocation, additional cost of capital for corporations and barrier to efficient portfolio allocations for investors with clear impact on efficiency of an economy (Biais, et al., 2005).

In spite of taking into account frictions and costs in securities exchanges, that literature is based on the market efficiency hypothesis and tries to explain within that framework the gaps between the actual and the theoretical functioning of the markets. As a consequence, its goal in normative terms is to find the conditions which would help facilitating and accelerating the convergence of short term prices towards long term ones, the latter being supposed to reflect the fundamental values of the traded securities, even if fully efficient allocations are in general not achieved (Biais, et al., 2005). It is clear that market microstructure theory in its standard development does not cope with theories questioning the very existence of a fundamental value or arguing that prices can fluctuate durably far from this value.

Nevertheless, recent developments of market microstructure deal with behavioral finance and try to integrate traders' psychology in the models in order to explain overconfidence of informed traders and hoarding behaviour of both informed and liquidity traders, phenomena which lead to volatility excess and bubbles (Madhavan, 2000). On the other hand, the distinction between short and long term impact of trades leads to question on how short is the short term and how long the long term is. Very recent high frequency trading techniques in developed financial markets seem to suggest that the short term horizon of prices might be measured in nanoseconds. At the opposite end, if the long term convergence were to slow, one should wonder about the exogeneity of information and fundamentals to price formation.

Microstructure analysis is inherently involved with analyzing the detailed functioning of a marketplace. The literature has a strong theoretical component and, to a large extent, is structured to yield insights into the effect of market design on market performance (Francioni, et al, 2010). Market microstructure deals with the financial 
intermediation in the process of trading financial securities. In a trading market, assets are not transformed - as they are, for example, by banks that transform deposits into loans - but are simply transferred from one investor to another. The financial intermediation service provided by a market is immediacy (Sinnakkannu, 2006). An investor who wishes to trade immediately is a demander of immediacy and one does it by placing a market order to trade at the best available price - the bid price if selling or the ask price if buying. Suppliers of immediacy establish the bid and ask prices. Depending on the market design, suppliers of immediacy may be professional dealers that quote bid and ask prices or investors that place limit orders, or some combination.

Where the participants in the securities market behave rationally and have the same information, share prices will at all times reflect all available information about firms' fundamental value. Since it was first advanced in the 1960 s, this has been one of the most important hypotheses in financial economics. However, over the years, both the theoretical foundation for this hypothesis and the previously strong empirical support for it have been challenged. The microstructure literature challenges the hypothesis of efficient markets by studying how prices can deviate from or converge towards informationally efficient equilibrium prices as a result of rational participants behaving strategically (Biais et al., 2004). Strategic behaviour can be put down to unequal access to information or to limited liquidity in the secondary market. While the EMH abstracts from the actual process which leads to buyers and sellers finding one another and agreeing on a price, the microstructure literature focuses on the functions performed by the marketplace.

Themes in the microstructure literature are divided into three (Naes \& Skjeltorp, 2006): the actual transaction process, the effects of market structure and trading rules on the transaction process, and the transaction process's implications for fundamental economic decisions. This subdivision also largely reflects the chronological development of this research field. There are two main groups of models of transaction process. The first (inventory models) studies how an intermediary (like dealers) can solve the problem of buyers and sellers not being present in the market simultaneously. The second (information models) analyses how information which is asymmetrically distributed between participants in the market is reflected in the prices of securities. Research into the significance of market structure and trading rules is the subject of this study. The importance of the organization and design of the securities market came to the fore in the wake of the crash of 1987 and the revelation of collusion among the dealers on NASDAQ in 1994. There has since also emerged a considerable body of literature on the effects of market fragmentation and competition from new electronic trading systems.

Microstructure research rejects the hypothesis that the transaction process and the organization of markets have no effect on the prices of securities. Some studies elsewhere have looked at whether the securities market's microstructure can also have long-term effects on prices and returns. The development of market microstructure as a subject has coincided with a period of establishment of new securities markets and revitalization of existing markets in many developing and transitional economies (Jallow, 2009). The revitalization of these emerging securities markets is typically characterized by institutional reforms, including modernization of the trading and information systems, expanding securities market membership, revamping the regulatory framework, and opening access to foreign capital (Okumu, 2013; Onyuma, et al., 2012). The developments are aimed at improving securities market performance by increasing liquidity and transparency, enhancing efficiency, and reducing volatility and trading costs (Kariuki \& Onyuma, 2012). The wider goal is to promote the development of local capital markets and facilitate access to long-term capital.

The main issue in securities markets is whether and how market microstructure changes can create a positive value in terms of liquidity, efficiency, price discovery, and volatility. Previous studies on more established markets, which have implemented changes in trading systems, have reported a positive impact, creating gains in market efficiency, increased liquidity and lower volatility. These include studies in Milan (Amihud, et al., 1990), Tokyo (Amihud \& Mendelson, 1991) and Tel Aviv (Amihud, et al., 1997). Blennerhassett \& Bowman (1998) reported a fall in transactions costs on the New Zealand Stock Exchange following the move from open-outcry to screen trading, and Majnoni \& Massa (2001) report broadly positive results after implementing market microstructure changes in terms of trading regulations and transaction cost introduced by the Italian Stock Exchange. There are fewer such studies in emerging markets, and their results are more mixed.

Masulis \& Shivakumar (2001) studied how different stock markets with different market microstructure affect the speed with which new information is incorporated into prices in the US and the finding suggest that differences in market microstructure can significantly accelerate or retard the incorporation of news into market prices. Some findings suggest that the entry of foreign investors is an important factor than internal market reform (although the former may be predicated on the latter), and that this is followed by increased liquidity and enhanced market efficiency, with market volatility either remaining unchanged or declining (Ngugi, et al., 2002). Sunday (2011) has found increased market turnover and liquidity in Nigerian securities market following installation of an ATS. However, Chang, et al. (1999) found no change in liquidity or in the efficiency of the price discovery process, while volatility increased, following the introduction of a continuous auction system in Taipei Stock Exchange.

However, the central idea of market microstructure change is to gain market efficiency. Securities markets are constantly thriving to implement changes in market microstructure, which is most obviously driven by the 
rapid structural, technological, and regulatory changes affecting the securities industry worldwide. The causes of these structural shifts are complex. They include the substantial increase in trading volume, competition between exchanges within the same country and regions, the introduction of Electronic Communications Networks (ECNs), changes in the regulatory environment, technological innovations, the growth of the Internet usage, and the proliferation of new financial instruments. When the relevant market microstructures are changed in tandem with the said changes the market is expected to gain efficiency.

\subsection{Empirical Analysis of Market Automation and Efficiency}

Technological changes have revolutionized the way financial securities are traded nowadays. Every step of the trading process, from order entry to trading venue to back office, is now highly automated, dramatically reducing the costs incurred by market intermediaries. By reducing the frictions and costs of trading, technology has the potential to enable more efficient risk sharing, facilitate hedging, improve liquidity, and make prices more efficient. This could ultimately reduce firms' cost of capital.

Securities exchanges worldwide are moving from physical trading platforms to computer based system automated trading. Although numerous studies have been conducted on the effects of automation, most of the studies examine the effect of automation on market characteristics such as volume, liquidity and volatility. Few studies have formally examined the effect of automation on information efficiency. For instance, Amihud et al (1997) using an event study method observed that the Tel Aviv Stock Exchange greatly benefited from the change in trading system. Securities that were selected for transfer from the call auction system to the continuous trading system posted positive gains due to liquidity improvements. Olujide (2000) found evidence that the automation of the Nigeria Stock Exchange in 1997 through the introduction of CDS and the ATS had a positive impact on the liquidity of the market, transparency, investor confidence and foreign investment.

Other studies for instance, Majnoni \& Massa (2001) found evidence of increased efficiency at the Italian Stock Exchange after microstructure reforms (creation of specialised intermediaries, obligation to trade on the official markets, screen-based trading and cash settlement). Alam et al (2011) found that despite the numerous policy reforms undertaken at the Dhaka Stock Exchange the market was still inefficient at the weak form. The few studies that have formally examined the effect of automation on efficiency have reported mixed outcomes. For example, Sinnakkannu \& Nassir (2006) found that micro-structural changes (introduction of computerized trading, central depository system and clearing and settlement) implemented by Bursa Malaysia reduced the time to equilibrium, that is, speed for information adjustment from 14 days to 9 days in 2001. Freund \& Pagano (2000) found that the level of informational efficiency remained unchanged during the automation period although the Toronto Stock Exchange showed improvement in efficiency when compared to the New York Stock Exchange.

On the contrary, Maghyereh (2005) found no evidence of improved efficiency following the automation of the Amman Stock Exchange. Similarly, Debysingh \& Watson (2007) found that the Jamaican Stock Exchange and the Trinidad \& Tobago Stock Exchanges were informational inefficient both before and after market automation. Although the authors caution that their results should be interpreted with caution due to data limitations encountered. Sioud \& Hmaied (2003) study of the automation of the Tunis Stock Exchange found higher trading volume with no reduction in volatility or price error, thus no improvement in market efficiency.

Empirical evidence further shows that even an increase in trading hours can lead to improved efficiency. For instance, Chauhan \& Argawal (2010) found that increased trading hours in the Indian Stock Market had the following ramifications; it reduced the influence of the SGX Nifty Futures on the S\&P CNX Nifty, reduced the volatility of returns in the S\&P CNX Nifty, increased trading volume and liquidity and increased foreign institutional investor participation.

Many market participants now employ algorithmic trading, commonly defined as the use of computer algorithms to automatically make certain trading decisions, submit orders, and manage those orders after submission, as opposed to using a broker. From a starting point near zero in the mid-1990s, algorithmic trading is thought to be responsible for as much as 73 percent of trading volume in the United States in 2009 (Hendershott et al., 2011). Automated trading through algorithmic order processing has been found to narrow the stock quote spreads, reduces adverse selection and trade -related price discovery, thereby improving stock and overall market liquidity and enhance the informativeness of the stock quotes (Hendershott et al., 2011). The above review focused on the effects of automation mostly from developed countries. However, given the developments that have taken place at the NSE and the lack of evidence on the effects of automation particularly from an emerging market perspective, this study ventured to close this gap.

Securities Markets Efficiency in Africa. Studies on weak form efficiency have been conducted on various securities markets in Africa. In general, there are wide disagreements on whether these markets are weak form efficient or not. To begin with, using parametric test (auto-correlation and variance ratio test) and non-parametric tests including runs test, Simon \& Laryea (2004) examined the weak form efficiency in securities markets in South Africa, Ghana, Mauritius, and Egypt and found only South Africa to be weak form efficient. On the contrary, Mlambo \& Biekpe (2005) studied 10 other stock markets in Africa individual stocks returns adjusted for thin 
trading, and found Kenya, Zimbabwe and Namibia - due to its dual listings with JSE - to be weak form efficient, with inefficiency reported in Ghana, Mauritius, Egypt, Botswana and BVRM exchanges.

Ntim et al. (2007) also examined the weak form efficiency in the Ghana Stock Exchange using robust test the variance ratio test developed by Lo \& Mackinlay (1988) and found weak form inefficiency. This is in line with the findings reported by Mlambo \& Biekpe (2005) but contrary to the findings of Simon \& Laryea (2004). Additionally, Kalu (2008) found that the returns in the Nigeria Stock Exchange are not normally distributed and do not follow a random walk. In contrast, Okpara (2010) concluded that the Nigerian Stock Exchange was weak form efficient using an All Share Index data, and a series of runs test and autocorrelation test. In addition, a review of security markets in Africa by Jefferis \& Smith (2005) concluded that the Nigerian market was not weak form efficient and shows no tendency towards efficiency.

Securities Market Efficiency in Kenya. A number of efficiency studies have been conducted at the Kenya securities market. However, these studies provide mixed evidence on the efficiency of the NSE. Using runs tests and autocorrelation analysis, Dickinson \& Muragu (1994), Mlambo \& Biekpe (2005), Magnusson and Wydick (2002), Mlambo \& Biekpe (2005), Rioba (2003), Omuchesi (2014) have findings implying that the NSE is weak form efficient. In addition, have found the market to be weak form efficient. On the other hand Parkinson (1987), Jefferis \& Smith (2005), Atiti (2005), Onyuma (2009), Aduda \& Chemarum (2010), Atogo (2010), Kakiya (2010) all have reported findings suggesting the NSE is weak form inefficient, while Mokua (2003) found no evidence of the weekend effect at the NSE.

Furthermore, Masinde et al., (2013) measured the effect of IPO announcement on market returns at the NSE using logistic regression method and found a positive effect. While Kariuki \& Onyuma (2012) used non-parametric tests and found market legal reforms to have a positive impact on returns, Owido, Onyuma \& Owuor (2013) used general auto-regressive conditional heteroskedasticity $(\mathrm{GARCH})$ approach and reported that market returns at the NSE were non-random as current returns were dependent on previous 3-day returns. The above studies provide mixed evidence of weak form efficiency at the NSE, warranting further research on securities market efficiency in Kenya.

In relation to relationship between automation and market performance, two studies comes to the fore. Using prices of securities listed at the NSE, Mbugua (2007) identified the behaviour of volume, volatility and liquidity under three trading systems: manual trading, CDS and ATS with a view to determine whether automation had affected the three market characteristics, and revealed that automation was associated with increased volume of trading, increased volatility of the listed shares and increased liquidity. Greater volumes of trade and volatility were noted when NSE was full automated compared to manual or partial automated systems. However though there was a noted increase in liquidity on introduction of CDS, but the liquidity declined on introduction of ATS. Using variance ration approach, Njuguna (2016a) assessed whether technological advancements have led to an increase in the market efficiency at the NSE between 2001 and 2015 and arrived at findings which suggests that advancement in technology has contributed to the increase in the market efficiency. Surprisingly, Njuguna (2016b) using serial correlation found that the NSE was not weak form efficient during the same period.

There has recently been an upsurge of activity in this market due to economic and legal reform, privatization and relaxation of restrictions on foreign investors (Ntil et. al., 2011) and automation of the trading and depository systems. With the recently installation and updating of the CDS and ATS at the NSE, the informational efficiency of the market is an issue of concern (Onyuma, 2017; Onyuma 2009). However, all the above studies have not determined the possible impact of the automation of the trading system on adaptive market efficiency of the Nairobi Securities Exchange. It is therefore not evident whether Exchange is efficient at which form or that the market automation has improved the level market efficiency.

\section{Research Methodology}

This study applied a longitudinal research design as it emphasizes the status of time and the study of a phenomenon over time. It also involved taking repetitive measures overtime for the purpose of comparing efficiency in the preautomation and post-automation periods. The use of the time is a design characteristic in which the extent of a phenomenon is measured after successive time period, and the effect of intervention influences are time related (Sekaran \& Bougie, 2016), and data is collected several times, before and after an intervention. This design was therefore suitable in analyzing and comparing the behaviour of returns during these two periods.

\subsection{Data Type \& Data Collection}

The NSE currently has sixty-three (63) listed firms, out of which four (4) are currently suspended from trading. In 2008, the Exchange created the NSE All Share Index (NASI), which on each trading day, computed using the prices of all the listed share of listed companies. The target population for the study therefore comprised of all the listed companies forming the NASI during a trading period. The NASI is calculated, by the Exchange, using the base-weighted aggregate approach also known as the market capitalization/value weighted methodology, meaning that the NASI level reflects the total market value of component stocks relative to a particular base period. 
The Index measures the performance of all listed firms, providing investors with a comprehensive and complementary set of indices, to measure the performance of the major capital and industry segments in Kenya. The index is designed to act as a barometer of the Kenyan economy with a view that companies listed on the NSE are a good representation of the sectors in which they operate. The objective of its construction was to provide the market with a composite report on market performance of all listed securities so as to highlight general trends in the market and the Kenyan economy (NSE, 2008). It is also a good benchmark for portfolio holders as they are able to measure the performance of their respective portfolio against the overall market. The Index tracks the daily performance of the market and acts as an indicator of the general market performance. Since the NSE All Share Index already considers the whole population, it can be said that the sampling procedure adopted by the study was one of census.

Using a data collection sheet, daily secondary data on stock prices (1993-2007) and the NASI (2008-2019) for September 1994 to September 2019 was collected from the NSE. The period represent when the Exchange experienced both subdued and superior trading activity when the NSE 20 Share Index, the only stock index then, recorded 980 points in 2001 and 6161 points in 2007.

Picking a base year of 1993 and a market capitalization of $31^{\text {st }}$ December 1992 and pegging a value of 100 points, this study used stock prices for all the firms listed and computed an All Share Index (market capitalization for the trading day divided by market capitalization for the base year) for the period 1994-2007 to take care for the period before the NASI was constructed. The index values computes together with NASI values collected were then split into pre-automation period ( $2^{\text {nd }}$ January $1994-31$ st December 2004), constituting 2519 trading days, and post-automation period ( $2^{\text {nd }}$ January $2005-31^{\text {th }}$ December 2019), constituting 3779 trading days. The key market microstructure changes implementation dates were obtained from the NSE and CMA media center archives and press release at www.nse.co.ke and www.cma.org, respectively.

\subsection{Variable Measurement \& Data Analysis}

The calculated and collected daily return on the NSE All Share Index was then computed as the first difference of the logarithmic stock index to reduce any problem of autocorrelation, and a test conducted to determine whether they were related to different market microstructure conditions. The study used non parametric tests to assess the randomness and independency of the data. The advantage of nonparametric test statistics is that they allow the derivation of specific critical values by simulating the exact sampling distribution (Mertens, Pugliese \& Recker (2017). Normality tests were also performed using skewness, kurtosis and Ryan-Joiner to test the distribution of returns. The efficiency of the market was then tested using the Runs test to uncover any return independency. Finally, the Wilcoxon signed rank test was then employed to determine the impact of automation on the price discovery process at the NSE. All these tests were conducted using Minitab Software Package, version 17.

A key assumption underlying the use of logarithms is that returns are more likely to be normally distributed which is a condition for standard statistical techniques (Mertens, et al., 2017). The daily return on the Index (NASI $\mathrm{R}_{\mathrm{t}}$ ) was computed consistent with (Washer, et al., 2011) as the first difference of the logarithmic price index as below (because stock price index movement is usually exponential from one period of time to another, rather than linear):

NASI R $_{t}=\left(\left(\operatorname{LnNASI}_{t}\right)-\left(\operatorname{LnNASI}_{t-1}\right)\right) /\left(\operatorname{LnNASI}_{t-1}\right)$

Where:

NASI $\mathrm{R}_{\mathrm{t}}=$ Daily market returns for NASI for day $t$

$\mathrm{NASI}_{t}=$ Closing value of the NASI for day $\mathrm{t}$.

$\mathrm{NASI}_{\mathrm{t}-1}=$ Closing value of the NASI for day $\mathrm{t}-1$.

Ln = Natural Logarithm.

The key assumption underpinning the use of logarithm in this study is that stock returns are not only lognormal, but they also are traded on a continuous basis (Simons \& Laryea, 2004).

Normality Tests for the Distribution of Market Returns. The random walk hypothesizes that in an efficient market, successive residual increments follow a normal distribution (Kalu, 2009). The standard measures for deviations from normality are skewness and kurtosis. Theoretically, the skewness of a normal distribution is zero and the Kurtosis of a normal distribution is 3. Positive skewness means that the distribution has a long right tail and negative skewness implies that the distribution has a long left tail. If the kurtosis of a distribution exceeds 3 , the distribution is peaked relative to the normal. However, if the Kurtosis is less than 3, the distribution is flat relative to the normal.

There are also several tests for normality which uses different calculations, such as Anderson-Darling, Shapiro-Wilk, Ryan-Joiner and Kolmogorov-Smirnov (Currell \& Dowman, 2009). Of these, the Ryan-Joiner test is easier to perform and interpret (Ryan \& Joiner, 1976). Granted, normality tests were performed using skewness, kurtosis and Ryan-Joiner test. Skewness was used as a measure of asymmetry of the distribution of a series around its mean, while kurtosis was used as a measure of the peakedness or flatness of the distribution. Using the Minitab Software package, the Ryan Joiner was further used to confirm whether the market returns were 
normally distributed. These measures have been widely used in other efficiency studies (Jefferis \& Smith, 2005; Okpara, 2010; Kariuki, 2011; Kariuki \& Onyuma, 2012).

Testing the Impact of Automation on Price Discovery Process. The Wilcoxon signed-rank test is a nonparametric statistical hypothesis test used when comparing two related samples, matched samples, or repeated measurements on a single sample to assess whether their population mean ranks differ - that it, is a paired difference test. It can be used as an alternative to the paired Student's t-test, t-test for matched pairs, or the t-test for dependent samples when the population cannot be assumed to be normally distributed (Mason et al., 2002).

The Wilcoxon signed rank test was employed to determine whether the change in market microstructure through Exchange automation had a positive effect on the price discovery process. The null hypothesis tested was that the median returns earned before market automation was not significantly different from the median returns after market automation. Failure to reject the null hypothesis would mean that market automation had no impact on the price discovery process of the Exchange.

In addition, Levene's test is an inferential statistic equivalent of the F-test and used to assess the equality of variances in different samples (Mertens, et al., 2017). Some common statistical procedures assume that variances of the populations from which different samples are drawn are equal. Levene's test assesses this assumption, by testing the null hypothesis that the population variances are equal - known as homogeneity of variance or homoscedasticity. If the resulting P-value of Levene's test is less than some critical value, typically 0.05 , the obtained differences in sample variances are unlikely to have occurred based on random sampling from a population with equal variances. Thus, the null hypothesis of equal variances is rejected and it is concluded that there is a difference between the variances in the population. Therefore, the Levene's test was used to determine whether return volatility had reduced in the post automation period. The Levene's test is particularly robust where data is not normally distributed and can therefore be used to infer on the level of market efficiency.

Test for Market Efficiency. Runs test can be used to assess return distribution and infer on weak form efficiency. The test is regarded to be strong in capturing the random walk in prices as it disregards the properties of distribution. A run is a series of increasing values $(+)$ or a series of decreasing values (-). Therefore, a runs test determines whether successive securities price changes are independent of each other (Mertens, et al., 2017). For instance, if price changes are positively related it would be more likely that a $(+)$ sign is followed by a $(+)$ and a $(-)$ is followed by a (-). Under the null hypothesis of runs test, a series of runs is said to follow a random walk if successive price changes are independent. If a series of runs does not follow a random walk (dependent), the null hypothesis is rejected.

To determine whether a series is random, the expected number of runs was compared with the observed number of runs. In a random series the observed number of runs is closer to the expected number of runs. If the observed number of runs is fewer than the expected number of runs then the series may have positive autocorrelation. If the observed runs are more than the expected runs this may indicate negative autocorrelation. Thus, too few runs or too many runs indicate evidence against the random walk hypothesis (Reily \& Brown, 2011). Again, runs tests have been extensively used to test for serial independence of stock returns (Mlambo \& Biekpe, 2005; Okpara, 2010; Okumu, 2013).

\section{Discussion of Findings}

\subsection{Test of Normality Distribution of Market Returns}

The results from the skewness, kurtosis and Ryan-Joiner tests are presented in Table 1. The mean return in the post market automation period was higher than mean return in the pre-market automation period. The negative mean returns in both periods are an indication of the subdued market activity in both the periods of analysis. Similarly, the median return in the post automation period was higher than the median returns in the pre automation period. The standard deviation in the post automation period was also higher than the standard deviation in the pre automation period.

Table 1: Normality Distribution Tests of Market Returns

\begin{tabular}{|l|l|l|}
\hline Statistic & Pre Market Automation & Post Market Automation \\
\hline Mean & -0.005232 & -0.005923 \\
\hline StdDev & 0.22869 & 0.22764 \\
\hline Median & 0.01407 & -0.00063 \\
\hline Skewness & -40.890 & -40.467 \\
\hline Kurtosis & 1590.9075 & 1563.76 \\
\hline Ryan-Joiner & 0.1260 & 0.1386 \\
\hline RJ (p-value) & $<0.011$ & $<0.011$ \\
\hline Obsev (N) & 1562 & 2009 \\
\hline
\end{tabular}

The higher median return and standard deviation reported in the post market automation were also tested for significance. The random walk hypothesis posits that market returns should follow a normal distribution. In order 
to test for this property, the Skewness, Kurtosis and Ryan-Joiner tests were used. The results of these tests presented in Table 1 indicate the Skewness and Kurtosis values portraying a likely departure from normality in both periods as none had a Skewness value equal to zero and Kurtosis value equal to 3 . The returns in the premarket automation period are positively skewed, an indication that market returns in the pre-market automation had a long right tail and slightly peaked. However, the returns in the post market automation period were negatively skewed, an indication that the returns had a long left tail with a relatively flat peak. Although both periods are considered bearish periods, the negative skewness value in the post market automation period shows a greater chance of extreme negative values while the positive skewness value in the pre-market automation period imply a lesser chance of extreme negative values. These results are not surprising given that the NSE was adversely affected by the global financial crisis in 2007/2009 (Kilonzo, 2008) and debt crisis of 2011/2012, and the volatility was likely to arise from the changes in market microstructure following advances in the depository and trading systems.

A test for normal distribution was also conducted using the Ryan-Joiner test. The first null hypothesis of the study was that market returns in the two periods were both normally distributed. From Table 1, the p-values for the Ryan-Joiner tests for both the two periods are 0.011, means that at 5 percent level of significance, the null hypothesis of normal distribution is rejected for both periods. This result confirms the earlier finding that returns in the pre and post market automation periods are not normally distributed. Although it would have been expected that returns after market automations to closely approximate a normal distribution, the results confirm that returns in the Exchange exhibit stylized facts (Opong et al, 2010) - a characteristic of returns distributions, which are skewed and with fat-tails, and experience volatility clustering.

\subsection{Impact of Automation on Market Efficiency}

Did market automation had an impact on price discovery process? An efficient price discovery process ensures that investors realize the best prices for their stocks which should ideally be closer to the fundamental values. The introduction of market automation was expected to improve the efficiency of price discovery process by targeting liquidity and transparency among other factors. Therefore, if market automations have had a positive impact on the price discovery process, investors would lower their required rate of return due to increased liquidity and transparency and in turn securities prices should appreciate. In other words, the returns earned in the post market automation period would be higher than returns earned in the pre automation period. To test whether automation had a positive effect on the price discovery process, the Wilcoxon signed rank test was used. The Wilcoxon signed rank test is a non-parametric test for matched pairs and uses the median value. The null hypothesis was that returns in the post market automation period are not significantly different from returns in the pre-market automation period. A one tailed test was carried out at 5 percent significance level. The results of the test are presented in Table 2 .

Table 2: Impact of Market Automation on Market Returns

\begin{tabular}{|l|l|l|l|l|l|}
\hline & $\mathbf{N}$ & N for Test & Wilcoxon Statistic & P-Value & Estimated Median \\
\hline Diff (Post -Pre) & 6296 & 1262 & 1372.456 & 0.0394 & 0.20359 \\
\hline
\end{tabular}

The results in Table 2 show a p-value of 0.0394 while the alpha level for the test was 0.05 , indicating that the p-value was less than the alpha level for the test. Thus, at 5 percent significant level the study rejected the null hypothesis and concluded that returns earned in the post market automation period were higher than the returns earned in the pre-market automation period. These results confirm that the introduction of market automation had a positive impact on the price discovery process. This finding is in line with other studies that have shown that the introduction of market automation, particularly touching on the trading system, did improve the efficiency of the price discovery process at the Bursa Malaysia Exchange (Sinnakkmiannu \& Nassir, 2006). Green et al. (2002) also found positive price reactions due to improvement in liquidity following installation of BOLT in Mumbai Stock Exchange in India. Predictions of how market automation and faster order execution should affect the efficiency of price discovery are, however, mixed.

The speed of trading in a securities market is important because delay induces uncertainty about the probability of order execution and the price at which such execution may occur. Traders' risk aversion makes such uncertainty undesirable (Hendershott \& Moulton, 2011). Even if securities traders are risk neutral, many trading strategies are usually more difficult to implement with slower trade execution platforms. Strategies contingent on prices, strategies involving simultaneous trades in multiple securities, and strategies which break larger orders in to smaller orders all perform worse as order execution times increase. Boehmer, et al., (2007) find that a market centre receives more order flow when its reported execution speed increases.

If market automation and resultant trade execution speed reduce transaction costs, they should enable more efficient allocation of securities among heterogeneous investors, improve risk-sharing and consumption smoothing, and can raise asset prices (Acharya \& Pedersen, 2005). Market automation and the resultant trade execution speed may also enhance price discovery - or how efficiently new information is incorporated in to securities prices 
(Boehmer \& Kelley, 2009). More efficient price discovery contributes to better informed financing and investment decisions, benefiting shareholders by facilitating better corporate decisions.

Did market automation had an impact on market volatility? In an efficient market, securities prices are closer to fundamental values. However, when a market experiences excess volatility it leads to price distortions and market prices may not reflect the fundamental values. Although market efficiency is an idealization, interventions by market regulatory authorities, such as CMA, are meant to ensure that market prices closely approximate fundamental prices by touching on aspects such as liquidity and transparency. The introduction of market automation by the Exchange was expected to increase liquidity and transparency thereby enhancing market efficiency. Therefore, market automations would have improved market efficiency if there was reduced volatility in the post market automation period.

The study tested whether there was reduced volatility in the post market automation as compared to the premarket automation period. To test whether market automation has led to reduced volatility, the Levene test was used. This test is useful where data is not normally distributed and uses the median value in testing for equality of variances. The third null hypothesis of the study was that the variance of returns in the post market automation period was not statistically different from the variance of returns in the pre-market automation period. A one tailed test was carried out at 5 percent significance level, and the results presented in Table 3.

Table 3: Results of the Impact of Market Automations on Volatility

\begin{tabular}{|l|l|l|l|l|}
\hline Method: & DF 1 & DF & Statistic & P-Value \\
\hline F - Test & 1562 & 2009 & 3.752 & 1.000 \\
\hline Levene Test (any Continuous) & 1 & 108 & 8.191 & 0.997 \\
\hline Null hypothesis : Variance (Post automation) / Variance (Pre automation) $=1$ \\
\hline Alternative hypothesis: Variance (Post automation) / Variance (Pre automation) < 1 \\
\hline
\end{tabular}

The results in Table 3 show a p-value of 0.997 while the alpha level for the test was 0.05 . Thus, at 5 percent significance level, the study failed to reject the null hypothesis. This implies that volatility in the post market automation period did not reduce. Therefore, the results confirm that there was higher volatility in the post market automation period than in the pre-market automation period. Other works such as Sioud \& Hmaied (2003) found no significant effects on volatility or efficiency following automation of the Tunisian stock market. The higher volatility in the post market automation period could be attributed to the changes in the trading system.

Other studies have also found that price volatility is more in continuous auction markets than call markets due to trading frequency (Chang et al, 1998). Moreover, market automation is likely to increase the speed at which information is reaching the market thereby causing prices to fluctuate rapidly as they converge towards equilibrium (Naidu \& Rozeff, 1994). Hendershott \& Moulton (2011) found that market automation increases standard bid-ask spread measures of the cost of immediacy. With market automation, the spread widens just enough to compensate liquidity suppliers for the higher adverse selection. The increase in trading speed due to ATS may however, affect the cost of immediacy for traders. Introduction of ATS has therefore reduced the floor traders' advantage by increasing the anonymity of orders. The automated trading may also be providing faster feedback in terms of more up-to-date trades and quotes. These direct changes could also introduce indirect changes such as an increase in the working of orders and changes in the traders' patience, order arrival rate, and incentives to acquire information.

Although floor trading allows reputational benefits to arise from repeated human interaction on the trading floor (Battalio, et al., 2007), the reduction in floor trading brought about by the ATS makes reputations harder to sustain, which could lead to a breakdown in cooperation among colluding traders. Faster anonymous trading mechanisms has the ability to attract more informed trading (Barclay, et al., 2003). Faster execution in the ATS increases transparency by providing traders more up-to-date information about the state of the market. This could increase the ability of liquidity demanders to more closely monitor the market for temporary mispricings (Foucault, Roell \& Sandas, 2003). The resulting higher adverse selection may raise the cost of immediacy for liquidity demanders as they impose higher adverse selection costs on liquidity suppliers. Hendershott \& Moulton (2011) have also reported that spreads and adverse selection increase with market automation and that liquidity supplier profits do not decline, which are consistent with ATS having a more significant effect on liquidity demand than liquidity supply in Kenya.

\subsection{Test for Adaptive Market Efficiency}

Based on the Run Test were market returns independent of each other? Earlier, we found that the introduction of automation had a positive impact on the price discovery process. Similarly, we have also showed that the introduction of the market automation, especially ATS, had increased execution speed in the Exchange and may have led, probably, to higher costs of immediacy as adverse selection rises. The increase in the execution speed and informativeness of securities trades could also affect the efficiency with which information is incorporated into prices, depending on the balance between increased competition in liquidity provision, as in Goettler, et al. (2009) and the diminished role of a quasi-monopolist liquidity supplier, as in Leach \& Madhavan (1993). 
Therefore, the study tested whether market automation has led to improved market efficiency at the NSE. The non-parametric runs test was used to assess the efficiency of the market in the pre-market automation and post market automation periods. This test ignores the properties of the distribution and is robust especially where data is not normally distributed. If market automation had improved market efficiency, then the speed at which information is incorporated into securities prices should increase and so returns should become more random. The other hypothesis of the study was that market returns in the two periods were random and independent from one another. The runs test was performed using the median value, with the results for the pre market automation period and presented in Table 4.

From Table 4 below, the observed number of runs was 756 while the expected number of runs was 800 . The observed number of runs was closer to the expected runs which imply randomness in the return series. Additionally, the runs test results reveal a p-value of 0.0557 which is greater than the selected alpha level of 0.05 . Therefore, at 5 percent significance level the study failed to reject the null hypothesis. This implied that the returns in the premarket automation period followed a random walk.

Table 4: Results of Run Test for the Pre- Market Automation Period

\begin{tabular}{|l|l|}
\hline Run Tests & Statistic \\
\hline Runs above and below K & -0.008466339 \\
\hline The observed number of runs & 756 \\
\hline The expected number of runs & 800 \\
\hline Observations above K & 807 \\
\hline Observations below K & 791 \\
\hline P-value & 0.0557 \\
\hline
\end{tabular}

Similarly, the runs test results for the post market automation period presented in Table 5 below reveal that the observed number of runs was 756 while the expected number of runs was 800 . The observed numbers of runs are closer to the expected numbers of runs implying randomness of returns. Similarly, the p-value for the post automation period was 0.0667 , which is greater than the selected alpha level of 0.05 . Therefore, at 5 percent significance level, the study failed to reject the null hypothesis. This indicated that the returns in the post market automation period also followed a random walk.

Table 5: Results of Runs Test for the Post-Market Automation Period

\begin{tabular}{|l|l|}
\hline Run Tests & Statistic \\
\hline Runs above and below K & -0.00591964 \\
\hline The observed number of runs & 376 \\
\hline The expected number of runs & 531 \\
\hline Observations above K & 1233 \\
\hline Observations below K & 348 \\
\hline P-value & 0.0710 \\
\hline
\end{tabular}

Although results in both periods indicated that returns follow a random walk, a closer look at the results of the two periods showed that the number of observed runs in the post automation period was much closer to the expected number of run than it was in the pre-market automation period. This was also reaffirmed by the higher p-value of 0.0710 in the post market automation as compared to the p-values of 0.0557 in the pre-market automation period. Therefore, these results confirm that returns were more random in the post market automation period, an indication of improved market efficiency. These findings are in line with others that have reported positive gains in efficiency with the introduction of market automation (Maghyereh, 2005; Sunday, 2011; Debysing \& Watson, 2007). However, the findings differed with those by Freund \& Pagano (2000) who found non-random price behaviour for some stocks at the Toronto and New York Stock Exchanges following microstructure changes.

The volatility of the efficient price provides a measure of whether volatility increases reflect a change in the amount of information being incorporated into prices or an increase in noise. The increase in the efficient price volatility over the period following introduction of market automation indicates that the higher volatility is not simply noise, but reflects information being incorporated faster into prices. If prices follow a random walk, the number of observed runs should be equal or closer to the number of expected runs from a random return series, thus measuring the extent to which returns diverge from a random walk in either direction, so a decline in the difference between the observed and expected number of runs would indicate an increase in price efficiency, suggesting that price efficiency improves with the introduction of microstructure changes. These findings are consistent with Goettler, et al (2009), Jallow (2009) and Sunday (2011) predictions that price efficiency improves with market automation at the New York Stock Exchange, West African exchanges (Ghana and BVRM), and the Nigerian Stock Exchange, respectively. 


\section{Conclusions \& Policy Prescription}

On the question whether market automations has had an impact on market efficiency in Kenya, the results indicate that mean market returns in the post market automation period were higher and more volatile than those in the premarket automation period. This higher market returns can be attributed to improved price discovery process, while the higher volatility may be due to changes in market microstructure - the trading system. The results from normality tests also show that market returns are not normally distributed in both the periods, though it would have been expected that the post automation period would have closely approximated a normal distribution. As to the efficiency of the market, the runs test results reveal that market returns are more random in the period following automation than the prior period. This implies that the market has improved in efficiency.

These results point to the fact that when a market first starts trading, it takes time for the price discovery process to become known. As markets operate and market microstructures develop, emerging securities markets are likely to become more efficient. The changing efficiency in the two periods also provide support for the adaptive market hypothesis which posits that market efficiency undergoes cycles overtime as influenced by market environmental factors, in this case, automation of the trading system. The general conclusion of the study is that introduction of automation in the Kenyan securities market has led to improved market efficiency, thereby providing support for the adaptive market hypothesis.

It was observed that the introduction its automated trading system a few years after depository, clearance and settlement system increased the Exchange's automation process and speeded up its electronic trading. This must have led to a drop in the execution time for market orders, with the power to raise the cost of immediacy - the effective price spread and this increase may be attributable to higher adverse selection. The increase in adverse selection is accompanied by information being incorporated into prices more efficiently. Price efficiency is a public good that can inform corporate investment and financing decisions. A faster market can also enhance welfare by reducing risk-averse traders' uncertainty about the probability and price at which execution may occur. Furthermore, faster trading can facilitate more complex trading strategies.

Moreover, the cost of immediacy is a zero-sum transfer from liquidity demanders to liquidity suppliers. Calculating the aggregate welfare effects of changes in the cost of immediacy in markets with heterogeneous market participants requires a structural model with numerous assumptions about traders' utilities and strategies. If all traders follow the same strategies before and after the introduction of microstructure changes, the adverseselection-driven increase in the cost of immediacy implies transfers from uninformed to informed traders. Greater losses by uninformed traders can hinder risk-sharing, though. However, if automated trading system lowers the cost of information acquisition and more extreme private-value traders choose to become informed, then risksharing could be enhanced. The potential positive and negative welfare impacts of changes in the cost of immediacy can therefore preclude sharp determinations of the overall welfare impact of increasing order execution speed.

The main goal of the NSE and CMA is to enhance competition between markets and market intermediaries. By allowing faster automated markets to replace slower manual trading markets, the regulator's investor protection rules effectively preclude traditional floor trading because human interaction is too slow. The laudable goals of the NSE is to give investors, particularly retail investors, greater confidence that they will be treated fairly when they participate in the securities markets, and to promote deep and stable markets that minimize investor transaction costs - an objective which was embedded in the 2019 update in its depository and automated trading systems. Increasing the speed of order execution and the efficiency of prices formation likely gives investors greater confidence of fair treatment, but the move to faster electronic trading may raise the cost of immediacy through the adverse selection. Thus it may be challenging to meet both of these goals.

The new AMH views securities markets from an evolutionary prism through an attempt to reconcile market efficiency with human behaviour. It questions investors and markets are rational and efficient given the financial bubbles, crashes, and crises. Market environment including the microstructural advancements as well as human psychology and behaviour in themselves define how markets will adapt to these changes through an evolutionary process which requires deeper understanding of neuroscience, artificial intelligence and other fields that offer insight on human behaviour. Securities markets may not necessarily be efficient or not, but markets will be progressively adapting to the changing trading environment and evolving over time. This is because when securities markets are unstable, investors often react instinctively rather than rationally, creating inefficiencies for other investors and traders to exploit. Given the market swings between stability and crisis, profit and loss, and innovation and regulation, this new adaptation paradigm of looking at securities markets could explain how financial evolution speedily shapes behaviour and securities markets. So a complete understanding of efficiency of securities market should incorporate human behaviour to assess how it could be shaping efficiency evolution journey of a market.

In terms of policy prescription, the findings of this study are of importance for policy making, especially those interested in improving the efficiency of the Kenyan securities market. The main implication is that securities market automation is important in enhancing market efficiency. Market efficiency is a multi-faceted issue and can 
be enhanced by increasing market liquidity and transparency, reducing transaction costs and removing impediments to market access. Although variants of automations have been introduced in the Kenyan securities market to address liquidity and transparency, the market turnover is still low, as evident in the 2020 CMA first Quarter Bulletin, and access to the NSE by retail investors is still limited as all the stock broking firms are still located in Nairobi. Avenues worth considering include licensing more market makers, adoption of a hybrid trading system, introducing online and internet securities trading in Kenya, and harnessing the thriving mobile money transfer and payment systems.

First, Kenya has increasingly embraced ICT which may be attributed to the comparative lower cost of access to internet via computers and mobile phones. Therefore, the NSE and CMA should consider deepening automation of the market through adoption of both online and internet securities trading. Through these, investors would not have to travel to Nairobi where brokers have offices to trade in securities, but can rather log into the online trading platforms operated by brokers wherever they are and be able to access the electronic order book within the ATS of the Exchange. One area worth considering is the use of the Internet. Internet securities trading has been a success in developed securities markets in Europe and North America.

Therefore, to improve liquidity, securities markets policy makers should consider this avenue. In fact, ICT has made information describing the macro and micro environment of economies readily accessible to stakeholders making them better placed to access and act in markets in accordance with changing dynamics in the environment (Pal and Mittal, 2011). ICT is therefore expected to play a big role in making security markets efficient by driving security prices closer to their true values and therefore erasing trading patterns. This may result in the market becoming more efficient as information becomes readily and equally available and buyers are able to value securities fairly. This development would have the effect of increase the number of rational buyers in the market, none of whom can influence prices in the market, thus making the market more efficient.

Moreover, the adoption of a hybrid trading system can also assist in improving market liquidity. Other securities markets, such as the Tunisian Stock Exchange and NYSE have both a call and continuous system. The call system has been found to be more effective when dealing with thinly traded stocks while the continuous system is suited for heavily traded stocks. The market can open with the call system and then later changes to a continuous system for liquid stocks, as happens at the NYSE hybrid trading.

Furthermore, the licensing of more stock dealers - the market makers - can assist in improving liquidity. The NSE operates as a continuous limit order market where brokers receive potential buy/sell orders that are submitted in the automated trading system to be matched. This system suffers from one major weakness, the lack of immediacy. The lack of immediacy may result in order imbalances, which may lead to large price changes primarily because there is no party to stand ready to buy or sell the securities, and this is where market dealers become important.

In addition, Kenya has also been experiencing drop in the cost of accessing the Internet through mobile phone technology. Therefore, the CMA and NSE should work with the ICT industry practitioners in order to harness the benefits of mobile telephony so that the thriving mobile money financial framework can be meshed with the broker payment systems together with ATS and CDS in order to enable the securities buying, selling and making payments for such transactions through mobile money transfer system available in the country like M-Pesa, Orange Money and Airtel Money services and other emerging mobile money transfer platforms, such as Tangaza. The end result will be increase in market activity, enhanced liquidity and transparency, and heightened investor confidence, thus leading to improvement in securities market efficiency.

Lastly, the Exchange should however look to enhance its IT security infrastructure to secure online access to NSE systems by local and foreign investors. To benchmark NSE systems against best practice, the Exchange should also subject its security systems to audit by an independent and reputable third party. This is necessary given that the installation of the depository and automated trading systems in Kenya has witnessed an upsurge in fraudulent trading activities undertaken by brokers. Indeed, the electronic trading and depository systems have not stopped human manipulation to personal advantage, both by brokerage and CDSC staffs, despite the promised efficient monitoring of transaction and audit of broker activities.

\section{References}

Acharya, V., \& Pedersen, L. H. (2005) Asset Pricing with Liquidity Risk. Journal of Financial Economics, Vol. 77: $375-410$.

Alam, M., Yasmin, S., Rahman, M. \& Uddin, G. S. (2011) Effect of Policy Reforms on Market Efficiency: Evidence from Dhaka Stock Exchange, Economics Research International, 1(1): 1-8.

Amihud, Y. and Mendelson, H. (1987) Trading Mechanisms and Stock Returns: An Empirical Investigation, Journal of Finance, Vol.42:533-553.

Amihud, Y. \& Mendelson, H. (1991) Volatility, Efficiency and Trading: Evidence from the Japanese Stock Market. Journal of Financial Economics, Vol. 46: 1765-1789.

Amihud, Y., Mendelson, H. \& M. Murgia, M. (1990) Stock Market Microstructure and Return Volatility: Evidence 
from Italy, Journal of Banking and Finance, 14(2-3), 423-40.

Amihud, Y., Mendelson, H. \& Lauterbach, B. (1997) Market Microstructure and Securities Values: Evidence from Tel Aviv Stock Exchange, Journal of Financial Economics, 45: 365-390.

Amin, M. E. (2005) Social Science Research: Concepts, Methods and Analysis. Makerere University Printery: Kampala, Uganda.

Barber, B. and Odean, T. (2001) Boys Will Be Boys: Gender, Overconfidence, and Common Stock Investment. Quarterly Journal of Economics, Vol. 116: 261-229.

Barclay, M., Hendershott, T., \& McCormick, D.T. (2003) Competition Among Trading Venues: Information and Trading on Electronic Communication Networks. Journal of Finance, 58, 2637-2665.

Battalio, R., Ellul, A., \& Jennings, R. (2007) Reputation Effects in Trading on the New York Stock Exchange. Journal of Finance, 62: 1243-1271.

Biais, B., Glosten, L. \& Spatt, C. (2004) Market Microstructure: A Survey of Microfoundations, Empirical Results, and Policy Implications. CEPR Discussion Paper No. 3288.

Biais, B., L. Glosten \& Spatt, C. (2005) Market Microstructure: A Survey of Microfondations, Empirical Results and Policy Implication. Journal of Financial Markets, 8(2), 217-264.

Black, F. (1986). Noise. Journal of Finance, Vol.41: 529-44.

Blennerhassett, M. \& Bowman, R.G. (1998) A change in Market Microstructure: the Switch to Electronic Screen Trading on the New Zealand Stock Exchange. Journal of International Financial Markets, Institutions and Money, 8: 261-276.

Boehmer, E., 2005. Dimensions of execution Quality: Recent Evidence for U.S. Equity Markets. Journal of Financial Economics, 78: 463-704.

Boehmer, E., Jennings, R., \&Wei, L. (2007) Public Disclosure and Private Decisions: Equity Market Execution Quality and Order Routing. Review of Financial Studies, 20: 315-358.

Boehmer, E., \& Kelley, E., 2009. Institutional Investors and the Informational Efficiency of Prices. Review of Financial Studies, 22: 3563-3594.

Campbell, J.Y., Lo, A.W. \& Mackinlay, A.C. (1997). The Econometrics of Financial Markets. Princeton, NJ: Princeton University Press.

Chang, R. P., Hsu, S., Huang, N. \& Rhee, S. G. (1999) The Effects of Trading Methods on Volatility and Liquidity: Evidence from Taiwan Stock Exchange. Journal of Business Finance and Accounting, Vol. 26(1\&2): 137170.

Chauhan, A. K. \& Agarwal, K. (2010) Increased Trading Hours and its Post-Impact on Market Efficiency: Empirical Evidence from the Indian Stock Market. www.http://ssrn.com/abstract.

CMA (2012) Press Release on launch of Capizar Market Surveillance System. Issue No. 12 - July - September. Nairobi, Capital Markets Authority.

CMA (2013) Quarterly Statistical Bulletin: Quarter Ended March 2013, Issue 16/2013.

Coughenour, J. \& Shastri,K. (1999) Symposium on Market Microstructure: A Review of the Debondt, W.F. and Thaler, R. (1985). Does the Stock Market Overreact? Journal of Finance, Vol. 40: 793-805.

Currell, G. \& Dowman, A. (2009) Essential Mathematics and Statistics, 2nd Edition: Wiley-Blackwell.

De Bont, W. F. M. \& Thaler, R. (1985) Does the Stock Market Overreact? The Journal of Finance, Vol. 40 (3): 793-805.

Debysingh, N. \& Watson, P. K. (2007) Automation and Efficiency in Two Emerging Markets. Sir Arthur Lewis Institute of Social \& Economic Studies Working Paper, University of West Indies.

Demsetz, H. (1968) The Cost of Transacting. Quarterly Journal of Economics, 82: 33-53.

Dimson, E. and Mussavian, M. (2000) Market Efficiency. The Current State of Business Disciplines, Vol.3:959970

Doran, J. S., D. R. \& Peterson, et al. (2009) Confidence, Opinions of Market Efficiency, and Investment Behavior of Finance Professors. Journal of Financial Markets, In Press.

Fama, E. (1965) The Behaviour of Stock Market Prices. Journal of Business, Vol.38: 34-105.

Fama, E. (1970). Efficient Capital Markets: A Review of Theory and Empirical work, Journal of Finance, Vol.25; $383-417$.

Foucault, T., Kadan, O., \& Kandel, E. (2005) Limit Order Book as a Market for Liquidity. Review of Financial Studies, Vol. 18, 1171-1217.

Foucault, T., Roell, A., \& Sandas, P. (2003) Market Making with Costly Monitoring: an Analysis of the SOES Controversy. Review of Financial Studies, Vol. 16, 345-384.

Francioni, R., Hazarika, S., Reck, M. \& Schwartz, R. A. (2008) Equity Market Microstructure: Taking Stock of What We Know. The Road from Theory to a Real Marketplace is Indeed Bumpy. Journal of Portfolio Management. Fall Issue.

Francioni, R., Hazarika, S., Reck, M. \& Schwartz, R. A. (2010) Equity Security Market Microstructure: The Analysis of a Non-Frictionless Market. In Cheng-Few Lee. Alice C. Lee, and John Lee (editors), Handbook 
of Quantitative Finance and Risk Management, pp.333-352, Springer US.

Freund, W. And Pagano, M. S. (2000) Market Efficiency in Specialist Markets Before and After Automation. The Financial Review, Vol.35:79-104.

Goettler, R., Parlour, C., \& Rajan, U. (2009) Informed Traders and Limit Order Markets. Journal of Financial Economics, Vol. 93: 67-87.

Green, C. J., Manos, R., Murinde, V., \& Suppakitjarak, J. (2002) The Impact of Microstructure in Emerging Stock Markets: Evidence from Mumbai, India. A Final Draft of a Paper Presented at the International conference on Finance \& Development: Evidence and Policy Issues, Nairobi, July 10-1 ${ }^{\text {th }} 2001$.

Grossman, S. J. \& Stiglitz, J. E. (1980). On the Impossibility of Informationally Efficient Markets, American Economic Review, 70: 393-408.

Gu, A. Y. \& Finnerty, J. (2002). The Evolution of Market Efficiency: 103 Years Daily Data of Dow. Review of Quantitative Finance and Accounting, 18: 219-237.

Hautcoeur, P. C. \& Riva, A. (2011). Market Microstructure Over Time: An Agenda for Comparative European Research. Paper prepared for the EurHiStock Conference, April 29-30th. Paris, France.

Hendershott, T. \& Moulton, P. C. (2011) Automation, Speed, and Stock Market Quality: The NYSE's Hybrid. Journal of Financial Markets, 14:568-604.

Hendershott, T., Jones, C. M., \& Menkveld, A. J. (2011). Does Algorithmic Trading Improve Liquidity? The Journal of Finance, Vol. LXVI (1) (February):1-33.

Hurst, H. (1951). Long Term Storage Capacity of Reservoirs, Transactions of the American Society of Civil Engineers, 116, 770-799.

Ito, M. \& Sugiyama, S. (2009). Measuring the Degree of Time Varying Market Inefficiency. Economics Letters. 103: $62-64$

Jalloh, M. (2009) Microstructure of Capital Markets in West Africa: Issues and Challenges. Waifem Regional Course on Operations and Regulation of Capital Markets. July 27-31 ${ }^{\text {st }} 2009$, Accra, Ghana.

Kahneman, D., \& A. Tversky (1979). Prospect Theory: An Analysis of Decision Under Risk. Econometrica, 47 : $263-291$.

Kalra, S. (2010). Deeper Markets, Cheaper Capital. Finance \& Development, 44 (1):14-15.

Kariithi, K. (2001) The Role of the Nairobi Stock Exchange in Kenya. Presentation By Nairobi Stock Exchange Ltd Chief Executive to Students of The Columbia Business School. The 4th January. Nairobi.

Kariuki, R. K. \& Onyuma, S. O. (2012). Do Market Reforms Affect Securities Market Efficiency in Kenya? Application of the Adaptive Market Efficient Theory. Paper Presented at the International Conference on Mediating Crisis held at Laikipia University College 23-27 $7^{\text {th }}$ June. Nyahururu, Kenya.

Kim, J. H. \& Shamsuddin, A. f. (2008). Are Asian Stock Markets Efficient? Evidence from New Multiple Variance Ratio Tests. Journal of Empirical Finance, 15: 518-532.

Lagoarde-Segot, T. \& Lucey, B. M. (2008) Efficiency in Emerging Markets-Evidence from the MENA region. International Financial Markets, Institutions and Money, 18: 94-105.

Leach, C., Madhavan, A. (1993). Price Experimentation And Security Market Structure. Review of Financial Studies, 6: 375-404.

Lim, K. P., Brooks, R. D., \& Hinich, M. J. (2006). Testing the Assertion that Emerging Asian Stock Markets are Becoming More Efficient. SSRN Working Paper Series.

Lim, K., \& Brooks, R. (2011). The Evolution of Stock Market Efficiency over Time: A survey of the Empirical Literature. Journal of Economic Surveys. 25(1):69-108.

Lim, K., Brooks, R. D. \& Kim, J. H. (2008). Financial Crisis and Stock Market Efficiency: Empirical Evidence from Asian Countries. International Review of Financial Analysis, 17(3): 571-591.

Lo, A. W. (2017) Adaptive Markets: Financial Evolution at the Speed of Thought. Princeton University Press.

Lo, A.W., (2007). Efficient Markets Hypothesis The New Palgrave: A Dictionary of Economics: 1-22. New York: Palgrave McMillan.

Lo, A. W. (2004). Adaptive Market Efficiency: Efficiency from an Evolutionary Perspective. Journal of Portfolio Management. $30^{\text {th }}$ Anniversary Issue: $15-29$.

Lyons, R., (1999). The Microstructure Approach to Exchange Rates, MIT Press.

Madhavan A. (2000) Market Microstructure: A Survey. Journal of Financial Markets, 3:205-258.

Maghyereh, A. (2005). Electronic Trading and Market Efficiency in an Emerging Market: The Case of the Jordanian Capital Market. Emerging Markets Finance \& Trade, 41(4):5-19.

Majnoni, G. \& Massa, M. (2001) Stock Exchange Reform and Market Efficiency: The Italy Experience, European Financial Management, 7(1):93-115.

Majois C. (2008) Transparence et Microstructure de marché, 29(2): 5-50.

Mandelbrot, B. (1971): Analysis of Long-run Dependence in Economics: the R/S Technique, Econometrica, Vol. 39, (July Supplement): 68-69.

Mandelbrot, B. (1972) Statistical Methodology for Non-periodic Cycles: from Covariance to R/S Analysis. Annals 
of Economic and Social Measurement, 1: 257-288.

Maobe, A. K. (2012) Evaluation of Factors Affecting the Performance of Stockbrokers In Kenya. Unpublished MBA Project, Egerton University.

Masinde, J., Owuor, G., Onyuma, S. O., \& Njuguna, A. (2013) Effect of IPO Announcement on Market Returns of Listed Stocks at the Nairobi Stock Exchange. International Journal of Research in Management, 2(3):84119.

Mason, R. D., Lind, D. A. \& Marchal, W. G. (2002). Statistical Techniques in Business and Economics. Boston: Irwin/McGraw-Hill.

Masulis, R. \& Shivakumar, L. (2001) Price Reaction Speed to Stock Offering Announcements: A NYSE/AMEX and NASDAQ Comparison. Working Paper Vanderbilt University Nashville.

Mbugua, P. K. (2007) Impact of Stock Exchange Automation on Volume, Volatility and Liquidity of Stocks at Nairobi Stock Exchange. Unpublished MBA Project (University of Nairobi).

Mbuva, K. G. (2010) An Investigation into the Challenges Facing the Financial Performance of Stock Brokerage Firms in Kenya. Unpublished MBA Project (Kenyatta University).

Mertens, W., Pugliese, A. \& Recker, J. (2017). Quantitative Data Analysis for Accounting \& Information System Research. Switzerland: Springer.

Mlambo, C.; Biekpe, N. \& Smit E.M. (2003) Testing the Random Walk Hypothesis on Thinly Traded Markets: The Case of four African Stock Markets. The African Journal of Finance, 5 (1):16-35.

Naes, R. \& Skjeltorp, J. (2006) Is the Market Microstructure of Stock Markets Important? Economic Bulletin, 77 (3):123-132

Naidu, G. N. \& Rozeff, M. S. (1994), Volume, Volatility, Liquidity of the Stock Exchange Singapore before and after Automation, Pacific-Basin Finance Journal, 2: 23-42.

Ngatia, S. M. (2011) Effects of Automated Trading System of Bonds on Investors at the Nairobi Stock Exchange. Unpublished MBA Project (Kenyatta University).

Ngugi, R.W. (2000). Development of the Nairobi Stock Exchange: A Historical Perspective, KIPPRA, Discussion Paper No. 27. KIPPRA.

Ngugi, R.W., Murinde, V. \& Green, C. J. (2002) Does the Revitalization Process Really Enhance Stock Market Microstructure? Evidence from the Nairobi Stock Exchange. African Finance Journal, 4 (1): 32-63.

Njuguna, J. M. (2016a) The Changing Market Efficiency of the Nairobi Securities Exchange. Banks \& Banking System, 11(2): 70-80.

Njuguna, J. (2016b) Testing the efficient market hypothesis on the Nairobi Securities Exchange. Investment Management \& Financial Innovations, 13(3): 75-83.

NSE (2008) Ground Rules for Generation of NSE All Share Index. Nairobi: Nairobi Securities Exchange.

NSE (2009) Review of the NSE 20-Share Index Constituent Counters. Press Release. Nairobi: Nairobi Securities Exchange.

NSE (2011a) T+3 - Go Live Date July $4^{\text {th }}$ 2011. Press Release. Nairobi: Nairobi Securities Exchange.

NSE (2011b) Progress on Broker Back office (BBO) System for the Kenyan Market. Press Release. Nairobi: Nairobi: Nairobi Securities Exchange.

NSE (2011c) NSE 20 Share Index Review. Press Release. Nairobi: Nairobi Stock Exchange.

NSE (2012a) History of the Organization. Nairobi: Nairobi Stock Exchange.

NSE (2012b) Launch of The NSE Broker Back Office System. Nairobi: Press Release. Nairobi Stock Exchange.

Ntim, C.G. Opong, K. K. \& Dunbolt, J. (2007) An Empirical Re-Examination of the Weak Form Efficient Market Hypothesis of the Ghana Stock Market Using Variance Ratio Tests. African Finance Journal, 9 (2):

Odera, O. (2001) Determination of the Accuracy of the NSE 20 Share Index. Electronic Publications of Nairobi University SAP Project. Nairobi: University of Nairobi.

Okpara, G. C. (2010) Analysis of Weak-Form Efficiency on the Nigerian Stock Market: Further Evidence from GARCH Model. The International Journal of Applied Economics and Finance, Vol. 4(2): 62-66.

Okumu, A. N. (2013) Impact of Microstructure Changes on Market Efficiency of the Nairobi Securities Exchanges. Unpublished MBA Project (Kenyatta University).

Olujide, J.O. (2000) The Impact of Automation on The Nigerian Stock Exchange, Nigerian Journal of Banking and Financial Issues, 3(1):91-100.

Omuchesi, J. A. (2014). The Effect of Automation on Stock Market Efficiency: A Case of Nairobi Securities Exchange. Unpublished MBA Project (Egerton University).

Onyuma, S. O. (2020) Securities Markets Development in Africa: Mobile Financial Services, Efficient Remittance Flows \& Diaspora Investment Securities. Chennai: Notion Press Publishers.

Onyuma, S. O. (2021) Regulatory Reforms in the Kenyan Securities Market: Have They Achieved their Intended Objective of Market Development? (forthcoming).

Onyuma, S. O. (2017) Analysis of Financial Deepening Determinants Influencing Securities Market Development in Kenya. Unpublished PhD Thesis (Laikipia University, Kenya). 
Onyuma, S. O. \& Kibet, L. K. (2017). Does Economic Growth Influences the Relationship Between Financial Intermediaries and Securities Market Development In Kenya. Journal of Economics and Sustainable Development, 8(16): 19-30.

Onyuma, S. O. \& Ochieng', I. E. (2017). Moderating Effect of Economic Growth on the Relationship Between Foreign Private Capital Flows and Securities Market Development: Evidence from Kenya. Journal of Developing Country Studies, 7 (8): 1-13.

Onyuma, S. O. (2012). Capital Markets Development in Emerging Economies: Institutions, Macroeconomic and Microstructure Reforms Determining Stock Markets Development in Kenya. Saarbrucken, Germany.

Onyuma, S. O. (2011) Developing the Management and Ownership Structures of African Stock Exchanges. African Management Development Review, 10 (1): 35-66.

Onyuma, S. O. (2009) Day-of-the-Week and Month-of-the-Year Effect on the Kenyan Stock Market Returns. East African Social Science Research Review, Vol. XXV (2) June: 53-74.

Onyuma, S. O (2006a) Demutualization of Stock Exchanges in Africa: Prospects \& Problems. OSSREA Bulletin, 3(3): $36-46$.

Onyuma, S. O (2006b) Regional Integration of Stock Exchanges in Africa. African Review of Money Finance \& Banking (Supplementary Issue): 97-122.

Onyuma, S. O. and Mugo, R. K (2012) Does Cross-Border Listing (Still) Improve Firm Financial Performance? Journal of Business, Economics \& Finance, Vol.1 (1): 92-109.

Owido, P. K., Onyuma, S. O. \& Owuor, G. (2013) A GARCH Approach to Measuring Efficiency: A Case Study of Nairobi Securities Exchange. Research Journal of Finance and Accounting, 3(4):1-16.

Park, C. \& Irwin, S. H. (2007). What Do we Know About Technical analysis. Journal of Economic Surveys, 21(4): 786-826.

Peters, E. E. (1994). Fractal Market Analysis: Applying Chaos Theory to Investment and Economics. John Wiley \& Sons.

Reilly, F. K. \& Brown K. C. (2015). Investment Analysis and Portfolio Management, 10th Edition. Ney York: Thomson.

Ryan T A, \& Joiner B L (1976). Normal Probability Plots and Tests for Normality. Technical Report, Statistics Department, Pennsylvania State University.

Saadi, S., Gandhi, D., \& Dutta, S., (2006). Testing for Nonlinearity and Modelling Volatility in Emerging Capital Markets: The Case of Tunisia, International Journal of Theoretical and Applied Finance, 9, 1021-1050.

Sekaran, U., \& Bougie, R. (2016). Research Methods for Business: A skill Building Approach (5 ${ }^{\text {th }}$ ed.), West Sussex, UK: John Wiley \& Sons Ltd.

Sinnakkannu, J. and Nassir, A. M. (2006). Market Microstructure Changes and Time to Equilibrium (TTE)? Evidence Bursa Malaysia, International Research Journal of Finance and Economics, Issue No.6; 1-18.

Sioud, O. B. \& Hmaied, D. M. (2003). The Impact of Automation on Liquidity, Volatility, Stock Returns and Efficiency: Evidence from the Tunisian Stock Market. Review of Middle East Economics and Finance, 1 (2): $141-154$.

Stoll, H. (1999) Microstructure: The Organization of Trading and Short Term Price Behaviour, Vol. I \& II, Cheltenham, Edward Elgar.

Sunday, K. J. (2011). Microstructure Changes: Effect on Market Turnover in Nigerian Stock Market. Journal of African Macroeconomic Review, 1(1): 16-31.

Venkataraman, K. (2001). Automated Versus Floor Trading: An Analysis of Execution Costs on the Paris and New York Exchanges. Journal of Finance, 56: 1445-1885.

Walras, L. (1880), La bourse, la spéculation et l'agiotage, Bibliothèque Universelle et Revue Suisse.

Walras, L. (1882) La Bourse, la spéculation et l'agiotage. Eléments d'économie appliquée, Lausanne, F. Rouge, 1898 (1882): 401-45.

Washer, K., Nippani, S., \& Wingender, J., (2011). Day of the Week Effect in Canadian Money Market. Managerial Finance, 37(9): 855-866.

Yen, G. \& Lee, C. F. (2008) Efficient Market Hypothesis (EMH): Past, Present and Future. Review of Pacific Basin Financial Markets and Policies, 11: 305-329. 